\title{
A study on the characteristics of standing posture of elderly women with sarcopenia in Korea
}

\author{
Min-Jeong Kim, Tae-Young Kim, Yeon-A Choi, Ji-Hyoung Chin, Shin-Young Lee* \\ College of Education, Hankuk University of Foreign Studies, Seoul, Korea
}

This study intended to analyze the characteristics of standing posture and factors related to sarcopenia of elderly women in Korea to provide basic data for the development of rehabilitation programs designed to prevent and control of the sarcopenia of elderly women. A total of 194 elderly women, aged over 65 years old, living in Gyeonggi-do, were selected to diagnose the presence of sarcopenia through bioelectrical impedance analysis (BIA) and muscle function test (gait speed and grip strength). The subjects were then distinguished into normal group $(N G=92)$, presarcopenia group $(P G=86)$, and sarcopenia group $(S G=16)$; the standing posture of elderly women was captured with the three-dimensional (3D) imaging technique (PA200), and an analysis of variance (ANOVA) was carried out for the collected data through IBM SPSS Statistics ver. 23.0. The frontal measurements of standing posture, the pelvic level, R-patella center, and L-patella center, appeared with significant differences from each other whereas, the side measurements of standing posture, the R-earhole position, L-earhole position, R-shoulder position, L-shoulder position, R-pelvic angle, L-pelvic angle, R-knee position, and L-knee position, were also found with significant differences from each other. As a consequence, an intervention to be focusing on obese control was found necessary to prevent or to delay the presence of sarcopenia of elderly women. The positional displacement found from head, knee, and pelvis also necessitates the introduction of rehabilitation program customized for elderly women suffering the sarcopenia.

Keywords: Sarcopenia, Korean elderly women, Standing posture

\section{INTRODUCTION}

Aging accompanies diverse physiological changes affecting body composition (Ilich et al., 2014). Along with the increasing age, the body fat $(\mathrm{BF})$ is redistributed into abdominal fat while the muscle and bone are infiltrated by fat (Cruz-Jentoft et al., 2010). The amount of skeletal muscle has been reported to be decreasing approximately $0.8 \%$ every year after 40 years of age, $0.8 \%-1 \%$ for males or $0.64 \%-0.70 \%$ for females every year after 75 years of age (Grimby and Saltin, 1983; Mitchell et al., 2012). In particular, the loss of skeletal muscle of women appears involving with menopause (Maltais et al., 2009; Taaffe et al., 2005), reduces the muscular and physical strength, and increases the frequency of a fall and fracture leading to the potential increase of mortality (Cruz-Jentoft et al., 2010). These are thus evaluated as important health indicators of elderly women.
Sarcopenia is defined as reduced amount of muscle mass, reduced muscle strength, and reduced physical function (Chen et al., 2014) attributable to following factors: aging, decreasedamount of exercise, reduced intake of protein, sexhormone, and growth hormone, and changes of cytokine that causes inflammation etc. (Limpawattana et al., 2015).

World Health Organization assigned a nosological code (International Classification of Diseases, Tenth Revision, Clinical Modification code) to the sarcopenia in the early 2017, signifying it was recognized as an independent disease. Many previous studies reported sarcopenia, being involved with diverse factors deteriorating the health of senile people; the increased risk of a hurt from a fall, physical dysfunction, depression, deteriorated quality of life, and increase in the rates of hospitalization, morbidity, and mortality. Further, its relevance to osteoporosis, obesity, type II diabetes mellitus, cardiovascular disease, and metabolic disorder was also proved;

\footnotetext{
${ }^{*}$ Corresponding author: Shin-Young Lee (i) https://orcid.org/0000-0002-2482-6689 College of Education, Hankuk University of Foreign Studies, 107 Imun-ro, Dongdaemun-gu, Seoul 02450, Korea

Tel: +82-2-2173-3144, Fax: +82-2-2173-3934, E-mail: eshinyoung@hanmail.net Received: February 1, 2018 / Accepted: April 19, 2018
}

This is an Open Access article distributed under the terms of the Creative Commons Attribution Non-Commercial License (http://creativecommons.org/licenses/by-nc/4.0/) which permits unrestricted non-commercial use, distribution, and reproduction in any medium, provided the original work is properly cited. 
these suggest an important clinical significance of sarcopenia apparently (Janssen et al., 2002; Janssen, 2006; Jung et al., 2013; Kim et al., 2014b; Lim et al., 2010; Limpawattana et al., 2015).

Korea entered the aging society rapidly comparing to advanced countries. Along with the rapid increase in the population of aged people, the rapid increase in the expenditure of medical cost, particularly due to the increasing cases of sarcopenia and obesity, is predicted (Jung et al., 2017). Thus, the studies to be delving into issues related with the preparation of future society capable of saving medical cost are necessitated (Kim and Choi, 2013).

The efforts, trying to maintain healthy lives of aged people through the early detection of sarcopenia, active treatment thereof, and minimization of the changes in physical composition due to aging, need to be taken.

However, there are foreign diagnostic standards currently in use. This also necessitates further studies focusing on the establishment of spontaneous diagnostic standards that are clinically applicable.

The loss of muscle mass of elderly women brings them reduced muscular functionality and changed physique; this possibly be a cause of hurt from a fall (Rose, 2003). Besides, vertebral retroflexion refers to postural deformity in which the head is tilted forward (Balzini et al., 2003), which is due to aging at 20\%- $40 \%$ (Bartynski et al., 2005).

A $34 \%$ of elderly people aged over 65 years old were reported as members of a group of the risk of a hurt from a fall wherein, over $70 \%$ of them were reported as women (Kim et al., 2013). Thus, the issues related with posture and sarcopenia of old women are of concern to prevent them from a hurt induced by a fall.

As presented so far, effective information of sarcopenia of Korean old women available for clinical application are still insufficient. The subluxation, due to the loss of skeletal muscle, may bring dysfunction and a hurt caused by a fall thereby, increases the risk of death of old women. However, the studies, delved into the issues related with varying postural characteristics which are dependent on the loss of skeletal muscle, are few. Thus, this study intended for the identification of characteristics of erect standing posture of Korean old women, to be varying according to the presence of sarcopenia, to contribute to the solutions for health problems of senile women.

\section{MATERIALS AND METHODS}

\section{Participants}

The subjects participated in this study were selected from a
Table 1. Physical characteristics of subject $(n=194)$

\begin{tabular}{lr}
\hline Variable & \multicolumn{1}{c}{ Mean \pm SD } \\
\hline Age $(\mathrm{yr})$ & $76.72 \pm 5.71$ \\
Height $(\mathrm{cm})$ & $149.41 \pm 5.28$ \\
Weight $(\mathrm{kg})$ & $57.18 \pm 8.64$ \\
Fat free mass $(\mathrm{kg})$ & $36.76 \pm 4.00$ \\
Body fat $(\%)$ & $35.53 \pm 4.13$ \\
Body mass index $\left(\mathrm{kg} / \mathrm{m}^{2}\right)$ & $25.61 \pm 3.57$ \\
$\mathrm{ASM}^{\text {a) }}(\mathrm{kg})$ & $14.67 \pm 1.57$ \\
$\mathrm{SMl}^{\mathrm{b}}(\%)$ & $25.89 \pm 2.46$
\end{tabular}

SD, standard deviation; ASM, appendicular skeletal muscle mass; SMI, skeletal muscle index.

${ }^{\text {a) }} \mathrm{ASM}=\left[\left(\mathrm{Ht}^{2} / \mathrm{R} \times 0.104\right)+(\right.$ age $\times-0.050)+($ gender $\times 2.954)+($ weight $\left.\times 0.055)\right]+5.663$, where $\mathrm{Ht}$ is height $(\mathrm{cm}), \mathrm{R}$ is bioelectrical impedance analysis resistance in $250 \mathrm{~V}$, and gender women is 0 (Kim et al., 2014). ${ }^{b /} \mathrm{SMl}=\mathrm{ASM} /$ weight $\times 100$.

population of 200 senile women aged over 65 years, capable of standing alone and walking independently. Among the entire population, the 194 subjects, who understood the purposes of this study and agreed to participate in the study with respective written informed consent, were selected as subjects of this study. Physical characteristics of the 194 subjects are as summarized in Table 1.

\section{Measurement of sarcopenia}

To diagnose the presence of sarcopenia of each subject, the measurements of body composition and muscular function were collected. The subjects were suggested to wear light clothes to measure the body composition (weight, $\mathrm{BF} \%$, fat free mass, and body mass index $[\mathrm{BMI}])$. By using the mean value of resistance of the four extremities measured with BIA (ACCUNIQ BC360, SELVAS Healthcare, Inc., Seoul, Korea), the estimates of the mass of skeletal muscle were calculated through the formulae of appendicular skeletal muscle mass (ASM) (Kim et al., 2014a) and skeletal muscle index (SMI) (Lim et al., 2010).

\section{Measurement of muscle function}

The measurements of gait speed and grip strength were collected for the examination of muscular function. The stop watch was used to collect the measurements of gait speed of each subject walked freely for the distance of $4 \mathrm{~m}$; the total time of the walking distance of $4 \mathrm{~m}$ was collected with the precision of centisecond; and the index of 4/gait speed (sec) was calculated. The grip strength is highly correlated with systemic muscular strength; it can be substituted for the measurements of muscular strength of lower extremities; it can also be a measurement predicting consequences similarly to the measurement of lower extremities (Cesari 

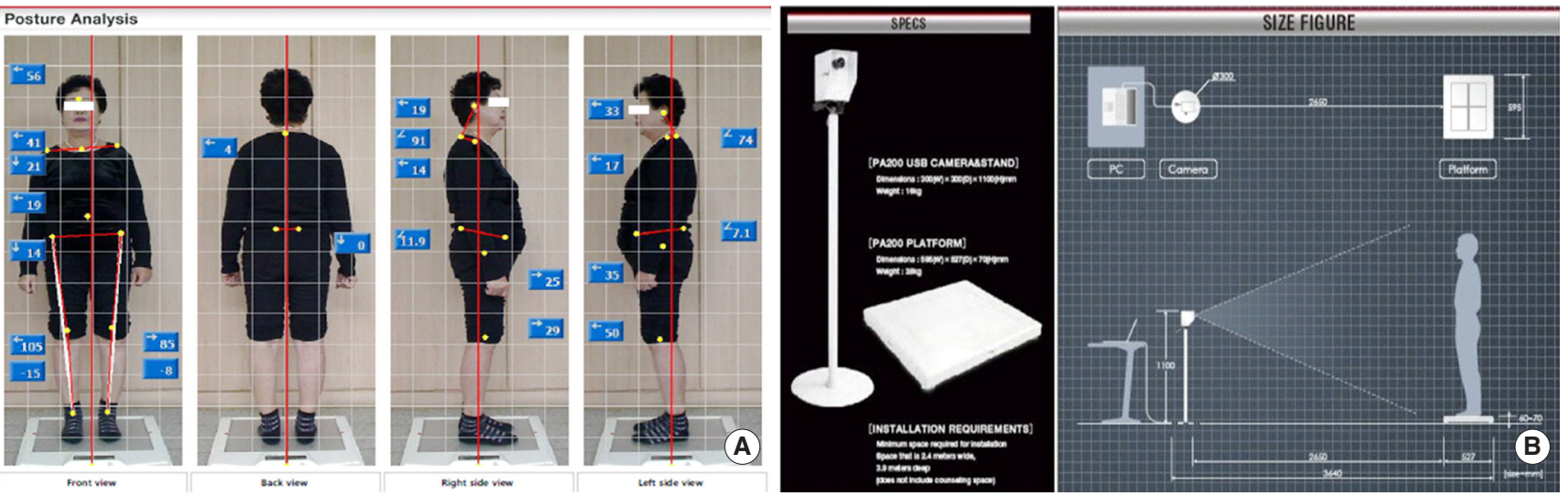

Fig. 1. Total measurement photos. (A) Attitude measurement by body image photo. (B) Shisei analysis system.

et al., 2006; Pahor et al., 2009). For the measurement of grip strength of each subject, the grip dynamometer (TKK-5401, Takei, Tokyo, Japan) was used to collect the two measurements from both hands of each subject; the highest value among entire measurements was recorded with the precision of $0.1 \mathrm{~kg}$.

\section{Sarcopenia diagnostic}

To collect the diagnostics of sarcopenia, the algorithm and standards of muscular function (gait speed $<0.8 \mathrm{~m} / \mathrm{sec}$, grip strength $<18 \mathrm{~kg}$ ) presented by the Asian Working Group for Sarcopenia (Chen et al., 2014), and the SMI\% cutoff 23\%, the scope less than 2 standard deviation (SD) of the 1,268 young females presented by Korea National Health and Nutrition Examination Survey IV (2008-2009) of Kim et al. (2012), were applied to the diagnosis of sarcopenia. Thereby, the entire subjects were classified into the groups of $\mathrm{NG}$ ( $\mathrm{n}=92$; normal muscular functionality and mass of skeletal muscle), PG ( $\mathrm{n}=86$; low muscular functionality and ordinary mass of skeletal muscle), and SG ( $\mathrm{n}=16$; low muscular functionality and mass of skeletal muscle).

\section{Measurement of standing posture}

For the measurement of standing posture of subjects, the Shisei innovation system (PA200, The Big Sports Co., Osaka, Japan), enabled to identify the kept balance of postural alignment through an analysis of systemic posture and physique of $3 \mathrm{D}$ image of subjects, operated by experienced clinical specialist, was used.

The equipment can measure the anterior, posterior, left-side, and right-side postures of subject distinguished by the median line. In this study, the front-postures, comprising the head level, shoulder level, pelvis level, central position of the left and right patella and the side-postures comprising the position of ear hole, position of shoulder, angle of pelvis (angle between the anterior superior iliac spine and the posterior superior iliac spine), position of femur, and position of knees, were used. The picture of measurement with an attachment of markers is as presented in Fig. 1.

\section{Data analysis}

All the data collected in this study were analyzed through the IBM SPSS Statistics ver. 23.0 (IBM Co., Armonk, NY, USA). After distinguishing each group of subjects according to the diagnostics of sarcopenia, the one-way ANOVA was carried out to identify the variables related with the loss of skeletal muscle mass and characteristics of each position of standing posture. The post hoc analysis was carried out with scheffe; the level of statistical significance for all statistics was set $\alpha=0.05$.

\section{RESULTS}

The results, obtained from the comparison of body composition and diagnostic factors of each group, are as summarized in Table 2.

The following variables related with the loss of skeletal muscle were all found with significant differences between each group: age $(P<0.001$, SG, $\mathrm{PG}>\mathrm{NG})$, height $(P<0.001, \mathrm{PG}<\mathrm{NG})$, weight $(P<0.001, \mathrm{SG}>\mathrm{PG}, \mathrm{NG}), \mathrm{BF} \%(P<0.001, \mathrm{SG}>\mathrm{PG}$, NG), BMI $(P<0.001$, SG $>$ PG, NG), ASM $(P<0.05, \mathrm{PG}<\mathrm{NG})$, SMI\% $(P<0.001, \mathrm{SG}<\mathrm{PG}, \mathrm{NG}), \mathrm{GS}(P<0.001, \mathrm{SG}<\mathrm{PG}<\mathrm{NG})$, and grip strength $(P<0.001, \mathrm{SG}, \mathrm{PG}<\mathrm{NG})$. The results, obtained from the comparison of the characteristics of standing posture, are as presented in Table 3 .

In the front posture, the measurements of pelvic level $(P<0.01$, SG $>$ NG), R-patella center $(P<0.001, P G>N G)$, and L-patella center $(P<0.01, \mathrm{SG}, \mathrm{PG}>\mathrm{NG})$ were found with significant dif- 
Table 2. Characteristics of sarcopenia diagnostic factors and body composition by group

\begin{tabular}{|c|c|c|c|c|c|c|}
\hline Variable & $S G(n=16)$ & $P G(n=86)$ & $N G(n=92)$ & $F$ & $P$-value & Scheffe \\
\hline \multicolumn{7}{|l|}{ Body composition } \\
\hline Age (yr) & $79.44 \pm 5.24$ & $78.88 \pm 5.72$ & $74.23 \pm 4.71$ & 20.028 & $0.000^{* * *}$ & $S G, P G>N G$ \\
\hline Height (cm) & $148.46 \pm 6.62$ & $147.70 \pm 5.34$ & $151.17 \pm 4.38$ & 10.914 & $0.000^{* * *}$ & $\mathrm{PG}<\mathrm{NG}$ \\
\hline Weight (kg) & $66.63 \pm 10.41$ & $54.28 \pm 7.58$ & $58.25 \pm 7.88$ & 17.731 & $0.000^{* * *}$ & $\mathrm{SG}>\mathrm{PG}, \mathrm{NG}$ \\
\hline $\mathrm{BF}(\%)$ & $41.84 \pm 1.81$ & $34.65 \pm 3.75$ & $35.25 \pm 3.83$ & 26.347 & $0.000^{* * *}$ & $S G>P G, N G$ \\
\hline $\mathrm{BMI}\left(\mathrm{kg} / \mathrm{m}^{2}\right)$ & $30.13 \pm 3.28$ & $24.90 \pm 3.36$ & $25.48 \pm 3.27$ & 16.932 & $0.000^{* * *}$ & $\mathrm{SG}>\mathrm{PG}, \mathrm{NG}$ \\
\hline \multicolumn{7}{|l|}{ Diagnosis factor } \\
\hline ASM (kg) & $14.67 \pm 2.06$ & $14.32 \pm 1.58$ & $15.01 \pm 1.39$ & 4.461 & $0.013^{*}$ & $P G<N G$ \\
\hline SMI (\%) & $22.07 \pm 0.80$ & $26.48 \pm 2.29$ & $26.00 \pm 2.22$ & 27.879 & $0.000^{* * *}$ & $\mathrm{SG}<\mathrm{PG}, \mathrm{NG}$ \\
\hline Gait speed (m/sec) & $0.56 \pm 0.05$ & $0.63 \pm 0.12$ & $0.87 \pm 0.06$ & 171.809 & $0.000^{* * *}$ & $\mathrm{SG}<\mathrm{PG}<\mathrm{NG}$ \\
\hline Grip strength (kg) & $17.08 \pm 4.78$ & $16.50 \pm 3.09$ & $22.48 \pm 3.05$ & 80.295 & $0.000^{* * *}$ & $\mathrm{SG}, \mathrm{PG}<\mathrm{NG}$ \\
\hline
\end{tabular}

Values are presented as mean \pm standard deviation. Gait speed $(\mathrm{m} / \mathrm{sec})=4 /$ time index.

SG, sarcopenia group; PG, presarcopenia group; NG, normal group; BF, body fat; BMl, body mass index; ASM, appendicular skeletal muscle mass; $S M I$, skeletal muscle index. ${ }^{*} P<0.05$. ${ }^{* *} P<0.001$.

Table 3. Characteristics of standing posture by group

\begin{tabular}{|c|c|c|c|c|c|c|}
\hline Variable & $S G(n=16)$ & $P G(n=86)$ & $N G(n=92)$ & $F$ & $P$-value & Scheffe \\
\hline \multicolumn{7}{|l|}{ Standing posture } \\
\hline Head level (mm) & $19.13 \pm 10.08$ & $22.95 \pm 15.77$ & $18.28 \pm 14.71$ & 2.253 & 0.108 & - \\
\hline Shoulder level (mm) & $12.44 \pm 7.92$ & $10.19 \pm 7.51$ & $8.82 \pm 6.74$ & 2.051 & 0.131 & - \\
\hline Pelvic level (mm) & $8.56 \pm 5.82$ & $7.88 \pm 6.37$ & $5.42 \pm 3.86$ & 5.827 & $0.003^{* *}$ & $S G>N G$ \\
\hline \multicolumn{7}{|l|}{ Patella center (mm) } \\
\hline Right & $101.38 \pm 15.49$ & $105.40 \pm 18.89$ & $93.77 \pm 14.29$ & 11.030 & $0.000^{* * *}$ & $\mathrm{PG}>\mathrm{NG}$ \\
\hline Left & $101.38 \pm 19.61$ & $101.41 \pm 21.45$ & $91.68 \pm 12.45$ & 7.396 & $0.001^{* *}$ & $S G, P G>N G$ \\
\hline \multicolumn{7}{|l|}{ Earhole position (mm) } \\
\hline Right & $27.88 \pm 22.79$ & $39.88 \pm 28.23$ & $20.15 \pm 17.57$ & 16.269 & $0.000^{* * *}$ & $\mathrm{PG}>\mathrm{NG}$ \\
\hline Left & $43.63 \pm 24.62$ & $40.45 \pm 28.58$ & $27.37 \pm 20.58$ & 7.389 & $0.001^{* *}$ & $S G>N G$ \\
\hline \multicolumn{7}{|l|}{ Shoulder position (mm) } \\
\hline Right & $21.00 \pm 15.65$ & $26.95 \pm 22.34$ & $16.52 \pm 14.83$ & 6.994 & $0.001^{* *}$ & $P G>N G$ \\
\hline Left & $17.56 \pm 15.95$ & $26.90 \pm 21.50$ & $16.85 \pm 13.52$ & 7.577 & $0.001^{* *}$ & $P G>S G, N G$ \\
\hline \multicolumn{7}{|l|}{ Pelvic angle $\left(1^{\circ}\right)$} \\
\hline Right & $18.37 \pm 5.69$ & $15.58 \pm 6.78$ & $12.87 \pm 5.52$ & 7.772 & $0.001^{* *}$ & $S G>N G$ \\
\hline Left & $19.28 \pm 5.34$ & $14.85 \pm 6.90$ & $12.32 \pm 5.78$ & 9.782 & $0.000^{* * *}$ & $S G>P G, N G$ \\
\hline \multicolumn{7}{|l|}{ Femur position (mm) } \\
\hline Right & $27.00 \pm 17.19$ & $32.83 \pm 17.54$ & $35.10 \pm 15.05$ & 1.770 & 0.173 & - \\
\hline Left & $29.38 \pm 16.37$ & $28.23 \pm 16.63$ & $34.20 \pm 16.78$ & 2.940 & 0.055 & - \\
\hline \multicolumn{7}{|l|}{ Knee position (mm) } \\
\hline Right & $37.63 \pm 17.71$ & $41.31 \pm 24.55$ & $31.05 \pm 20.24$ & 4.831 & $0.009^{* *}$ & $P G>N G$ \\
\hline Left & $34.81 \pm 22.77$ & $45.62 \pm 23.81$ & $31.78 \pm 19.66$ & 9.118 & $0.000^{* * *}$ & $P G>N G$ \\
\hline
\end{tabular}

Values are presented as mean \pm standard deviation.

$\mathrm{SG}$, sarcopenia group; $\mathrm{PG}$, presarcopenia group; NG, normal group.

${ }^{* *} P<0.01 .{ }^{* * *} P<0.001$.

ferences between each group. Whereas, in the side-posture, measurements of R-earhole position $(P<0.001, \mathrm{PG}>\mathrm{NG})$, L-earhole position $(P<0.01, \mathrm{SG}>\mathrm{NG}), \mathrm{R}$-shoulder position $(P<0.01$, PG $>$ NG), L-shoulder position $(P<0.01, \mathrm{PG}>\mathrm{SG}, \mathrm{NG})$, R-pelvic angle $(P<0.01, \mathrm{SG}>\mathrm{NG})$, L-pelvic angle $(P<0.001, \mathrm{SG}>\mathrm{PG}$, NG), R-knee position $(P<0.01, \mathrm{PG}>\mathrm{NG})$, and L-knee position $(P<0.001, \mathrm{PG}>\mathrm{NG})$, were found with significant differences between each group. 


\section{DISCUSSION}

\section{Body composition \& sarcopenia diagnostic factors}

The prevalence and significance of sarcopenia are interpreted variously; an integrated comprehension thereof is thus unavailable yet. The muscle indicator is defined as the value less than $2 \mathrm{SD}$ of mean value of the indicators of ASM compensated by weight (Janssen et al., 2002) and compensated by height (Baumgartner et al., 1998) of the young reference group of the age between 20 to below 40 years old.

The ASM/height $(\mathrm{cm})^{2}$ indicator is based on the amount of skeletal muscles in the four extremities measured mainly with dual energy x-ray absorptiometry (DXA), and is suitable for the prediction of mortality due to the loss of skeletal muscle; it has advantages of higher level of reproducibility of measurement of the amount of skeletal muscle and relative accuracy of the measurement (Kim and Choi, 2013).

However, it is inadequate to Asian races, and has limitations in predicting the reduced mobility of senile people. The necessity to take the account of the amount of $\mathrm{BF}$ of female subjects of which $\mathrm{BF} \%$ is higher than male subjects, has been raised (Newman et al., 2003). In particular, the indicator obtained from the compensation of weight was found adequate and preferred to the indicator obtained from the compensation of height for the diagnosis of sarcopenia of elderly women (Kong et al., 2016; Wen et al., 2011). Thus, in this study, the SMI\% (ASM/weight $\times 100)$ indicator was used for the diagnosis of sarcopenia.

In Korea, the estimation formula which is crossly applicable for the identification of the correlation between BIA method and DXA, that could compensate the difference in cutoff attributable to different measurement method, was recently presented; this enabled the convenient and accurate field measurement (Kim et al., 2014a).

However, the cutoff thereof is yet to be presented thereby, the cutoff, which was employed in the large scaled study conducted by Kim et al. (2012) and Jung et al. (2013), with domestic senile people, was used in this study.

Prior studies have reported the prevalence of sarcopenia ranged $1 \%-24 \%$ of elderly females aged 65 years old and, up to $25.6 \%$ of the elderly females aged over 80 years old (Kim et al., 2012). Through the muscle indicator (SMI\%) employed in this study, Kim et al. (2012) and Jung et al. (2013) reported 11.8\% and $5.2 \%$ of the prevalence of sarcopenia respectively, which are somehow different from $8.2 \%$ of the prevalence of sarcopenia resulted in this study. This was concluded to be attributable to the differ- ent definitions of the loss of muscle mass in prior studies that diagnosed the sarcopenia of subjects with the sole employment of muscle indicator excluded the muscular function.

In general, the subjects of BMI over 23 and $25 \mathrm{~kg} / \mathrm{m}^{2}$ are classified into groups of 'overweight' and 'obese' in Asian countries whereas, the subjects of BMI over $30 \mathrm{~kg} / \mathrm{m}^{2}$ are classified as those of the group of 'obese' subjects.

Diverse previous studies have reported the observed favorable states of health and low mortality of the elderly people belonged to the group of 'overweight' of its BMI $25-30 \mathrm{~kg} / \mathrm{m}^{2}$ (Flegal et al., 2013; Stenholm et al., 2008). These necessitate the new standards of obese indicators applicable to senile people (Kim and Choi, 2013).

Tyrovolas et al. (2016) suggested the prediction of sarcopenic obesity would be available with the SMI (\%) induced from body weight. The subjects in the group of SG participated in this study manifested significantly high BMI corresponding to this suggestion. The subjects in the group of PG were found with normal weight whereas, the subjects in the group of NG showed the characteristics of overweight.

Further, the gait speed of subjects in each group appeared in the following order of SG, PG, and NG, suggesting the subjects with sarcopenia correspond to lower gait speed whereas, the grip strength of subjects in the groups of SG and PG appeared lower than that of the subjects in the group of NG; this suggests the decreasing grip strength corresponding to the degree of the loss of muscle mass.

The subjects of the group of SG who exhibited lower level of muscular function also shared the characteristics of sarcopenic obesity. Baumgartner (2000) reported the risk of functional disorder, 11 times higher from women of sarcopenic obesity aged over 60 years. Baumgartner et al. (2004) participated in the 8-year follow-up study for subjects of sarcopenic obesity hosted by the New Mexico Aging Process Study; the authors reported the prevalence of physical disability of subjects of sarcopenic obesity 2-3 times higher than that of the subjects of either sole sarcopenia or sole obesity; supporting the results presented by Baumgartner (2000) and Baumgartner et al. (2004).

In the meantime, Kang and Park (2014) compared the subjects of senile females in groups of 'normal (BMI, $22.69 \mathrm{~kg} / \mathrm{m}^{2}$ )' and 'overweight (BMI, $27.35 \mathrm{~kg} / \mathrm{m}^{2}$ )' and, reported the subjects in the 'normal' group showed better posture control capability and efficient walking capability.

Due to the BMI of $25.48 \mathrm{~kg} / \mathrm{m}^{2}$ of the subjects of overweight which was close to normal weight of the subjects in the group of 
NG participated in this study, the favorable muscular functional capability of the subjects of NG seems ascribable thereto. Whereas, though the subjects of PG showed normal BMI, the less efficient walking capability of the subjects in the group of PG seems attributable to the significant difference in the muscle mass (ASM) from that of the subjects in the group of NG.

As the waking characteristics of normal elderly people undergoing normal degenerative process, the development of hip joint flexion, weakening of plantar flexion muscle and ankle joint, as well as low gait speed, are observed (Lee et al., 2002). The results obtained from this study also showed that the difference in muscular function was promoted by sarcopenic obesity. Thus, the obesity control of elderly women with sarcopenia should be prioritized to extend their life span.

\section{Standing posture}

Approximately $94 \%$ of overall degradation of physical function and strength are attributable to changes in musculoskeletal system (Balzini et al., 2003). And as a compensation for the loss of muscle fiber and resulting reduction of muscle force and physical damages thereof, the changes in alignment of posture and walking pattern of elderly people are frequently observed; these are followed by their head bent forward and posterior-anterior or lateral flexion of thoracic vertebra. The resulting posture signifies the limited mobility and inefficient walking of elderly people (Rose, 2003).

Unbalanced posture of senile people may cause low back pain, neck pain, and chronic pains, and it may bring them a significantly deteriorated quality of life or a hurt from a fall. Thus, in respect of the health of elderly people, the postural characteristics should be taken into account as well as the provision of suggestions for them to keep proper postures ordinarily.

In this respect, an ideal posture of body is accomplished with one's external auditory meatus aligned on the vertical line of body. From the body seen on the sagittal plane, the vertical line of body connecting to the external auditory meatus through crossing over slightly inside of anklebone, centerline of knees, and slightly behind the center of hip joint, constitutes an ideal posture of body (Haughie et al., 1995).

The system of posture control seems simple but, it requires complex control process of musculoskeletal system by which, the optimal posture of minimized muscular strain and physical load based on structurally balanced body, can be kept (Bae et al., 2001).

The bad posture of body, kept for a long while, may cause part of the body deviating from an original alignment of body. And to compensate the deviation, other parts of body subsequently move; this will promote the postural deformation resulting in the unbalanced posture of body (Perttunen et al., 2004).

The results obtained from the analyses of standing postures of the subjects in the group of SG participated in this study showed the observations of unbalanced postures which were comprised of the following: unbalanced height of pelvis, unbalanced central position of left knee, unbalanced left external auditory meatus, and unbalanced left and right angles of pelvis. Besides, the subjects in the group of PG of presarcopenia also manifested unbalanced postures with the right external auditory meatus, left and right shoulder positions, and left and right distance between the tibia lateral and the baseline.

The subjects in groups of SG and PG also exhibited the tendencies of anterior pelvic flexion deviated from the normal range of the angle of pelvis of $11.3 \pm 4.3$ (Levine and Whittle, 1996) with the forward flexed postural pattern characterized by the bending of knees and pelvic inclination (Lewis and Sahrmann, 2015).

In particular, the subjects in the group of SG showed significant difference of the angle of pelvis in the normal range. This was concluded to be attributable to the big frontal pelvis inclination owing to the pelvis, rotated to keep the erect position of the body of which weight inclined abdomen-ward of the subjects, in the group of SG characterized by the anterior pelvis tilt and obesity. The frontal pelvis inclination seems attributable to the reduced area of pelvic movement and decreased gait speed (Lee, 2013).

By comparing with the mean values obtained from the study conducted by Yang and Lee (2017) who analyzed the body alignment of healthy university female students by using the same posture measurement equipment, the subjects of the group of NG were observed with partial postural deformation due to aging from the positions of tilted head, of patellae of the center of knees, of hip joint, and of knees. However, these represented the standing posture more favorable than those of the subjects in groups of SG and PG.

Since the subjects, of which muscular function was beneath set standard but their muscle mass was higher than set cutoff, were mostly included in the group of the subjects of decreasing anterior muscle, the unbalanced posture partially identified from the group seems ascribable thereto.

The subjects, classified as members in the group of decreasing anterior muscle like the group of PG participated in this study, are reported as those of high risk of transference to sarcopenia (Landi et al., 2012). Thus, the preventive management for the 
subjects in the group of anterior muscle reduction needs to be introduced by distributing the subjects into the risk group of sarcopenia (Kong et al., 2016).

As a consequence, the study solely delved into the postural characteristics resulted from the presence of sarcopenia of subjects may not enable us to identify relationships of the factors involved therein. Further, because of the insufficient number of subjects participated in this study, the generalization of the apparent results obtained from this study may also be disturbed.

However, the significance of this study may be found from the trial intended for the identification of postural characteristics of elderly women suffering or related with sarcopenia. Thus, the results obtained from this study are expected to be contributing to the development of rehabilitation programs focused on the health management of elderly people suffering or involved with sarcopenia.

\section{CONFLICT OF INTEREST}

No potential conflict of interest relevant to this article was reported.

\section{ACKNOWLEDGMENTS}

This work was supported by Hankuk University of Foreign Studies Research Fund of 2017.

\section{REFERENCES}

Bae SS, Kim BJ, Lee KH. Study for muscle imbalance of head, neck, shoulder. J Korean Soc Phys Ther 2001;13:769-776.

Balzini L, Vannucchi L, Benvenuti F, Benucci M, Monni M, Cappozzo A, Stanhope SJ. Clinical characteristics of flexed posture in elderly women. J Am Geriatr Soc 2003;51:1419-1426.

Bartynski WS, Heller MT, Grahovac SZ, Rothfus WE, Kurs-Lasky M. Severe thoracic kyphosis in the older patient in the absence of vertebral fracture: association of extreme curve with age. AJNR Am J Neuroradiol 2005;26:2077-2085.

Baumgartner RN. Body composition in healthy aging. Ann N Y Acad Sci 2000;904:437-448.

Baumgartner RN, Koehler KM, Gallagher D, Romero L, Heymsfield SB, Ross RR, Garry PJ, Lindeman RD. Epidemiology of sarcopenia among the elderly in New Mexico. Am J Epidemiol 1998;147:755-763.

Baumgartner RN, Wayne SJ, Waters DL, Janssen I, Gallagher D, Morley JE. Sarcopenic obesity predicts instrumental activities of daily living disability in the elderly. Obes Res 2004;12:1995-2004.

Cesari M, Leeuwenburgh C, Lauretani F, Onder G, Bandinelli S, Maraldi C, Guralnik JM, Pahor M, Ferrucci L. Frailty syndrome and skeletal muscle: results from the Invecchiare in Chianti study. Am J Clin Nutr 2006;83:1142-1148.

Chen LK, Liu LK, Woo J, Assantachai P, Auyeung TW, Bahyah KS, Chou MY, Chen LY, Hsu PS, Krairit O, Lee JS, Lee WJ, Lee Y, Liang CK, Limpawattana P, Lin CS, Peng LN, Satake S, Suzuki T, Won CW, Wu CH, Wu SN, Zhang T, Zeng P, Akishita M, Arai H. Sarcopenia in Asia: consensus report of the Asian Working Group for Sarcopenia. J Am Med Dir Assoc 2014;15:95-101.

Cruz-Jentoft AJ, Baeyens JP, Bauer JM, Boirie Y, Cederholm T, Landi F, Martin FC, Michel JP, Rolland Y, Schneider SM, Topinková E, Vandewoude M, Zamboni M; European Working Group on Sarcopenia in Older People. Sarcopenia: European consensus on definition and diagnosis: Report of the European Working Group on Sarcopenia in Older People. Age Ageing 2010;39:412-423.

Flegal KM, Kit BK, Orpana H, Graubard BI. Association of all-cause mortality with overweight and obesity using standard body mass index categories: a systematic review and meta-analysis. JAMA 2013;309:7182.

Grimby G, Saltin B. The ageing muscle. Clin Physiol 1983;3:209-218.

Haughie LJ, Fiebert IM, Roach KE. Relationship of forward head posture and cervical backward bending to neck pain. J Man Manip Ther 1995; 3:91-97.

Ilich JZ, Kelly OJ, Inglis JE, Panton LB, Duque G, Ormsbee MJ. Interrelationship among muscle, fat, and bone: connecting the dots on cellular, hormonal, and whole body levels. Ageing Res Rev 2014;15:51-60.

Janssen I. Influence of sarcopenia on the development of physical disability: the Cardiovascular Health Study. J Am Geriatr Soc 2006;54:56-62.

Janssen I, Heymsfield SB, Ross R. Low relative skeletal muscle mass (sarcopenia) in older persons is associated with functional impairment and physical disability. J Am Geriatr Soc 2002;50:889-896.

Jung HW, Kim SW, Chin HJ, Kim CH, Kim KI. Skeletal muscle mass as a predictor of mortality in the elderly population. Korean J Med 2013; 85:167-173.

Jung SW, Seo MW, Kim SW, Song JK. Osteosarcopenic obesity is associated with reduced functional fitness, isokinetic muscle strength and relationships among irisin, adipokines and bone metabolism markers in elderly women. Korean J Sport Sci 2017;28:285-299.

Kang SW, Park YS. Difference of postural stability and gait by BMI level in the elderly. Korean J Growth Dev 2014;22:61-66.

Kim JH, Choi SH, Lim S, Kim KW, Lim JY, Cho NH, Park KS, Jang HC. Assessment of appendicular skeletal muscle mass by bioimpedance in older community-dwelling Korean adults. Arch Gerontol Geriatr 


\section{4a;58:303-307.}

Kim KS, Park KS, Kim MJ, Kim SK, Cho YW, Park SW. Type 2 diabetes is associated with low muscle mass in older adults. Geriatr Gerontol Int 2014b;14 Suppl 1:115-121.

Kim TN, Choi KM. Sarcopenic obesity. J Korean Diabetes 2013;14:166-173.

Kim YH, Yang KH, Park KS. Fall experience and risk factors for falls among the community-dwelling elderly. J Muscle Jt Health 2013;20: 91-101.

Kim YS, Lee Y, Chung YS, Lee DJ, Joo NS, Hong D, Song Ge, Kim HJ, Choi YJ, Kim KM. Prevalence of sarcopenia and sarcopenic obesity in the Korean population based on the Fourth Korean National Health and Nutritional Examination Surveys. J Gerontol A Biol Sci Med Sci 2012;67:1107-1113.

Kong SA. Sung SC. Kim HS. Efficacy in methods of sarcopenia diagnosis index. J Kinesiol 2016;18:15-23.

Landi F, Liperoti R, Russo A, Giovannini S, Tosato M, Capoluongo E, Bernabei R, Onder G. Sarcopenia as a risk factor for falls in elderly individuals: results from the ilSIRENTE study. Clin Nutr 2012;31:652-658.

Lee HJ, Lee CH, Yu EY. Correlations among the berg balance scale, gait parameters, and falling in the elderly. Phys Ther Korea 2002;9:47-66.

Lee KS. Study of Corrdlation between gait velocity and angle of pelvic of elderly women. J Korean Soc Neur Ther 2013;17:15-23.

Levine D, Whittle MW. The effects of pelvic movement on lumbar lordosis in the standing position. J Orthop Sports Phys Ther 1996;24:130135.

Lewis CL, Sahrmann SA. Effect of posture on hip angles and moments during gait. Man Ther 2015;20:176-182.

Lim S, Kim JH, Yoon JW, Kang SM, Choi SH, Park YJ, Kim KW, Lim JY, Park KS, Jang HC. Sarcopenic obesity: prevalence and association with metabolic syndrome in the Korean Longitudinal Study on Health and Aging (KLoSHA). Diabetes Care 2010;33:1652-1654.

Limpawattana P, Kotruchin P, Pongchaiyakul C. Sarcopenia in Asia; review article. Osteoporos Sarcopenia 2015;1:92-97.

Maltais ML, Desroches J, Dionne IJ. Changes in muscle mass and strength after menopause. J Musculoskelet Neuronal Interact 2009;9:186-197.
Mitchell WK, Williams J, Atherton P, Larvin M, Lund J, Narici M. Sarcopenia, dynapenia, and the impact of advancing age on human skeletal muscle size and strength; a quantitative review. Front Physiol 2012;3: 260.

Newman AB, Kupelian V, Visser M, Simonsick E, Goodpaster B, Nevitt M, Kritchevsky SB, Tylavsky FA, Rubin SM, Harris TB; Health ABC Study Investigators. Sarcopenia: alternative definitions and associations with lower extremity function. J Am Geriatr Soc 2003;51:16021609.

Pahor M, Manini T, Cesari M. Sarcopenia: clinical evaluation, biological markers and other evaluation tools. J Nutr Health Aging 2009;13:724728.

Perttunen JR, Anttila E, Södergård J, Merikanto J, Komi PV. Gait asymmetry in patients with limb length discrepancy. Scand J Med Sci Sports 2004;14:49-56.

Rose DJ. Fall proof. Philadelphia (PA): Human kinetics; 2003.

Stenholm S, Harris TB, Rantanen T, Visser M, Kritchevsky SB, Ferrucci L. Sarcopenic obesity: definition, cause and consequences. Curr Opin Clin Nutr Metab Care 2008;11:693-700.

Taaffe DR, Sipilä S, Cheng S, Puolakka J, Toivanen J, Suominen H. The effect of hormone replacement therapy and/or exercise on skeletal muscle attenuation in postmenopausal women: a yearlong intervention. Clin Physiol Funct Imaging 2005;25:297-304.

Tyrovolas S, Koyanagi A, Olaya B, Ayuso-Mateos JL, Miret M, Chatterji S, Tobiasz-Adamczyk B, Koskinen S, Leonardi M, Haro JM. Factors associated with skeletal muscle mass, sarcopenia, and sarcopenic obesity in older adults: a multi-continent study. J Cachexia Sarcopenia Muscle 2016;7:312-321.

Wen X, Wang M, Jiang CM, Zhang YM. Are current definitions of sarcopenia applicable for older Chinese adults? J Nutr Health Aging 2011; 15:847-851.

Yang MJ, Lee SY. Characteristics of body composition and posture alignment pursuant to regular exercise habit of female college students. Korean Soc Dance Sci 2017;34:109-120. 